Article

\title{
Effect of Ultrasound on the Oxidative Copper Leaching from Chalcopyrite in Acidic Ferric Sulfate Media
}

\author{
Jingxiu Wang *(D), Fariborz Faraji and Ahmad Ghahreman * \\ Hydrometallurgy and Environmental Group, Robert M. Buchan Department of Mining, Queen's University, \\ 25 Union Street, Kingston, ON K7L 3N6, Canada; f.faraji@queensu.ca \\ * Correspondence: jw219@queensu.ca (J.W.); ahmad.g@queensu.ca (A.G.)
}

Received: 10 June 2020; Accepted: 15 July 2020; Published: 17 July 2020

\begin{abstract}
The objective of this study is to compare the reaction kinetics of copper leaching from chalcopyrite in acidic ferric sulfate media with (UAL) and without (non-UAL) ultrasound assistance. Four leaching parameters were evaluated and optimized. The parameter with the strongest effect was temperature, followed by ultrasonic power, the solid-to-liquid ratio $(\mathrm{S} / \mathrm{L})$, and acid concentration. Copper recovery showed an increase with rising temperatures in both systems. Ultrasonic power had a positive effect on copper leaching, but no significant difference was found among various power amplitudes. Copper extraction increased with decreasing S/L. At $0.1 \% \mathrm{~S} / \mathrm{L}$, the UAL leaching rate was double the non-UAL leaching rate. In both systems, acid concentration had little effect on copper extraction. Under optimized conditions, $20 \%$ amplitude power, $1 \% \mathrm{~S} / \mathrm{L}, 0.5 \mathrm{M}$ acid, and $80{ }^{\circ} \mathrm{C}$ leaching temperature, copper extraction was $50.4 \%$ and $57.5 \%$ in the non-UAL and UAL treatments, respectively. Ultrasonic waves enhanced the leaching rate, shortened the reaction time, and reduced acid consumption. Analysis of the rate-controlling step using a shrinking core model showed that leaching occurs after diffusion through the product layer but also chemical controlled in both non-UAL and UAL systems. The leaching mechanism was confirmed by characterizing the chalcopyrite and leached residue with X-ray diffraction and scanning electron microscopy/energy dispersive X-ray spectroscopy.
\end{abstract}

Keywords: ultrasound; chalcopyrite; copper; sulfuric acid; leaching kinetics

\section{Introduction}

Chalcopyrite $\left(\mathrm{CuFeS}_{2}\right)$ is the most abundant copper sulfide mineral and the main copper-bearing mineral worldwide [1,2]. Chalcopyrite represents nearly $70 \%$ of known copper resources $[3,4]$. Pyrometallurgical smelting has been the industry-standard method to extract copper from high-grade chalcopyrite, but the use is restricted due to environmental problems (i.e., $\mathrm{SO}_{2}$ emissions) and the depletion of rich ore deposits increasing the processing costs [5,6]. Hydrometallurgical copper extraction is therefore an attractive alternative for treating low-grade chalcopyrite concentrate: it has higher metal recoveries, fewer air pollution hazards, and lower processing costs [7]. However, chalcopyrite is the most refractory copper-bearing mineral to hydrometallurgical leaching due to surface transformations that render the products very stable under oxidizing conditions [8]. In addition to ultra-fine grinding, numerous additives to leaching solutions have been proposed to promote chalcopyrite oxidation, including ferric sulfate $\left(\mathrm{Fe}_{2}\left(\mathrm{SO}_{4}\right)_{3}\right)$ in a sulfuric acid solution, efficient oxidants (e.g., $\mathrm{O}_{2}, \mathrm{H}_{2} \mathrm{O}_{2}$, and $\mathrm{O}_{3}$ ), microorganisms (bioleaching), $\mathrm{Ag}^{+}, \mathrm{Cr}^{6+}$, and $\mathrm{Cl}^{-}[9,10]$.

Leaching of chalcopyrite in ferric sulfate media has several advantages: it is easy to handle, does not cause corrosion, is low cost, and copper recovery by solvent extraction and electrowinning 
technologies is simple [11]. However, the dissolution of copper from chalcopyrite at ambient pressure and temperature in ferric sulfate media is typically low (less than $20 \%$ ), which has impeded its industrial application. In a sulfuric acid solution, oxidative leaching of chalcopyrite by ferric sulfate or dissolved oxygen (DO) obeys Reactions (1) and (2), respectively [12-14].

$$
\begin{gathered}
\mathrm{CuFeS}_{2}+2 \mathrm{Fe}_{2}\left(\mathrm{SO}_{4}\right)_{3} \rightarrow \mathrm{CuSO}_{4}+5 \mathrm{FeSO}_{4}+2 \mathrm{~S}^{0} \\
\mathrm{CuFeS}_{2}+4 \mathrm{H}^{+}+\mathrm{O}_{2} \rightarrow \mathrm{CuSO}_{4}+\mathrm{FeSO}_{4}+2 \mathrm{~S}^{0}+2 \mathrm{H}_{2} \mathrm{O}
\end{gathered}
$$

In both cases, ferric ion $\left(\mathrm{Fe}^{3+}\right)$ regenerates according to Equation (3) [15].

$$
4 \mathrm{FeSO}_{4}+\mathrm{O}_{2}+2 \mathrm{H}_{2} \mathrm{SO}_{4} \rightarrow 2 \mathrm{Fe}_{2}\left(\mathrm{SO}_{4}\right)_{3}+2 \mathrm{H}_{2} \mathrm{O}
$$

Researchers have divergent views on the steps governing chalcopyrite leaching since the mechanism of chalcopyrite dissolution by $\mathrm{Fe}^{3+}$ has not yet been elucidated [13]. Passivation has mainly been attributed to polysulfides, metal-deficient sulfides, jarosite, and elemental sulfur [16,17]. However, various studies have indicated the formation of elemental sulfur as a diffusion layer between the leaching solution and chalcopyrite, which might limit dissolution [18].

Various techniques have been tested to accelerate chalcopyrite dissolution during acidic ferric sulfate leaching, such as leaching at elevated temperatures (90-95 ${ }^{\circ} \mathrm{C}$ ), adding other reactants, or grinding chalcopyrite to very fine particles [19]. These techniques render the leaching process more energy- and time-consuming. In recent years, ultrasound has proven to be a powerful tool to enhance metal extraction in biological, chemical, electrochemical, and other hydrometallurgical leaching systems [20-22]. Ultrasound-assisted leaching (UAL) is gaining increasing attention because of the relatively low cost of ultrasonic power, availability of high-intensity ultrasound sources, environmental friendliness, as well as energy savings compared to other leaching techniques, such as pressurized or accelerated chemical leaching and toxic solvent extraction [21,23]. UAL has been shown to increase the dissolution of pyrite leached with ferric sulfate in a sulfuric acid solution by $30 \%$ [24]; the leaching rate of copper from a copper converter slag from $80.4 \%$ to $89.3 \%$ [25]; copper leaching of copper tailings in an ammonia solution by $13.5 \%$ to a total of $89.5 \%$ copper recovery [26]; and copper recovery from chalcopyrite leaching in an aqueous $\mathrm{FeCl}_{3}-\mathrm{HCl}$ solution by $10 \%$ [27].

The exact mechanism by which an ultrasound application affects leaching is not fully understood, but ultrasonic cavitation is the most predominant phenomenon for promoting metal extractions in ore processing. Cavitation has mechanical, chemical, and thermal effects [28]. For example, cavitation affects bubble dynamics in mechanical ways - oscillation, creation, growth, and collapse-to generate more energy. The chemical effects are then caused by free radicals and electron-exciting substance formation involving secondary reactions, improving the metal dissolution. The high-power, ultrasound-induced high kinetic energy of the water molecules, which can increase the solution temperature, then produce thermal decomposition.

In this study, ultrasound was applied to oxidize chalcopyrite in an oxygenated ferric sulfate-sulfuric acid solution with the aim of improving the copper leaching rate and(or) shortening the leaching time relative to non-ultrasound-assisted leaching (non-UAL) under the same conditions. The effects of ultrasound power, the solid-to-liquid ratio (S/L), sulfuric acid concentration, and leaching temperature on the leaching kinetics of copper from chalcopyrite were investigated and the optimum conditions were determined. The kinetic data were modeled using the classic Shrinking Core Model (SCM), and the rate controlling step was determined. The chalcopyrite and the leached residues obtained from UAL and non-UAL were characterized using X-ray diffraction (XRD) and scanning electron microscopy/energy dispersive X-ray spectroscopy (SEM-EDS). 


\section{Experimental}

\subsection{Materials}

Quantitative XRD analysis by X'Pert HighScore Plus software (Version 3.0e, PANalytical B.V., Almelo, The Netherlands) showed that the chalcopyrite-bearing ore sample was mainly composed of chalcopyrite $(57.9 \%)$, pyrite $\left(39.6 \% ; \mathrm{FeS}_{2}\right)$, and quartz $\left(2.5 \% ; \mathrm{SiO}_{2}\right)$ (Figure 1$)$. The chalcopyrite contained $18.2 \% \mathrm{Cu}$ (Table 1 ).

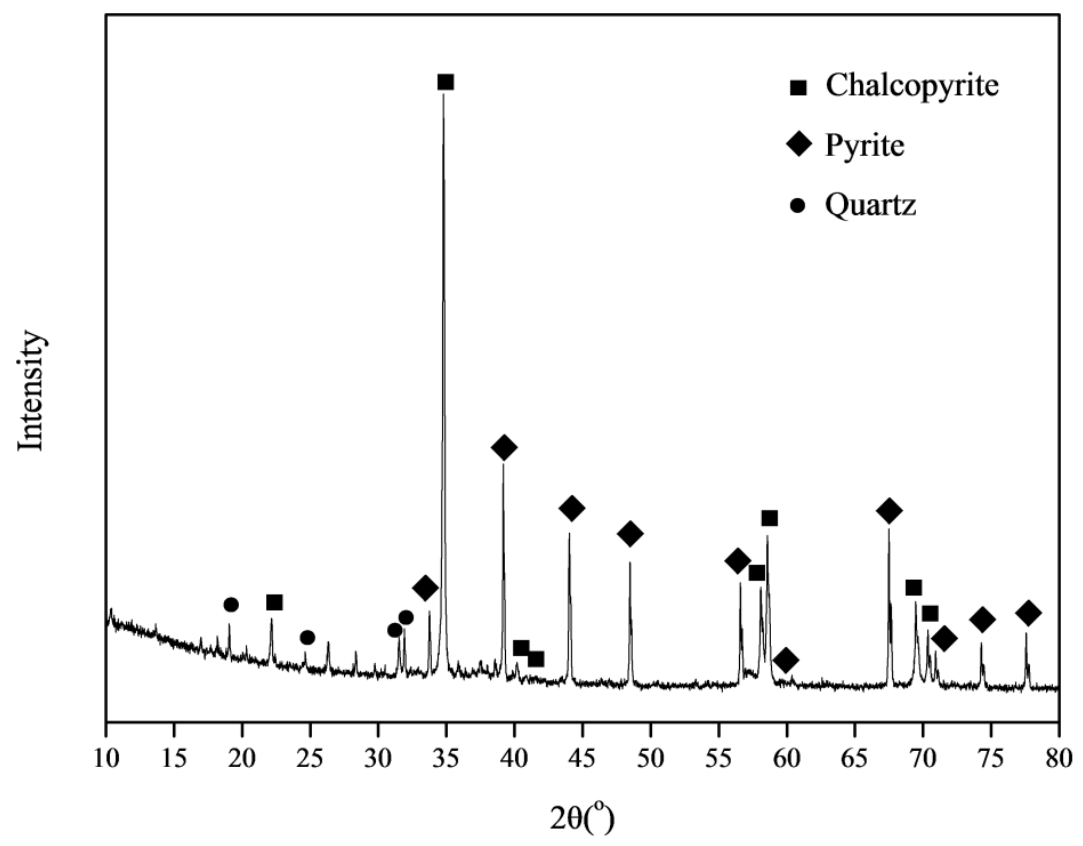

Figure 1. X-ray diffraction pattern of the chalcopyrite-bearing ore sample.

Table 1. Chemical composition of chalcopyrite from inductively coupled plasma optical emission spectrometry.

\begin{tabular}{ccccccccccccc}
\hline Chalcopyrite & $\mathbf{C u}$ & $\mathbf{F e}$ & $\mathbf{S}$ & $\mathbf{P b}$ & $\mathbf{Z n}$ & $\mathbf{A l}$ & $\mathbf{A s}$ & $\mathbf{C a}$ & $\mathbf{K}$ & $\mathbf{M g}$ & $\mathbf{P}$ & $\mathbf{N a}$ \\
\hline $\mathrm{wt} \%$ & 18.2 & 30.0 & 34.3 & 0.16 & 0.2 & 0.5 & 0.23 & 1.0 & 0.2 & 0.2 & 0.2 & 0.75 \\
\hline
\end{tabular}

SEM-EDS images (FEI Nova NanoSEM 450, FEI, Hillsboro, OR, USA) of the chalcopyrite ore revealed a smooth surface and a compact structure (Figure 2). EDS mapping data acquired and processed with ESPRIT software (Version 1.9, Bruker, Billerica, MA, USA) showed irregular dispersion of $\mathrm{Cu}$, but Fe and $\mathrm{S}$ were uniformly distributed as the highest proportions (Figure 3). As a result, pyrite was extensive on the ore surface, where chalcopyrite particles and some minor oxides were also evident. 


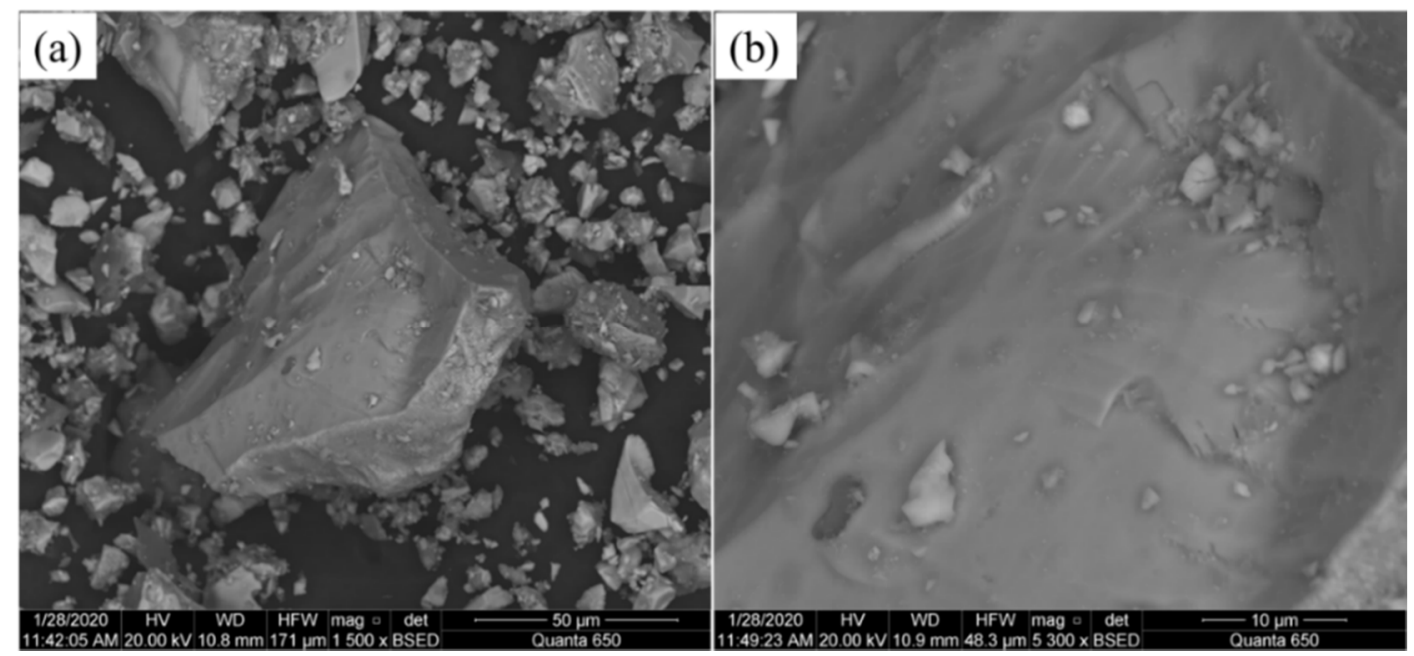

Figure 2. SEM images of the chalcopyrite-bearing ore at $(\mathbf{a}) \times 1500$ and $(\mathbf{b}) \times 5300$ magnification.

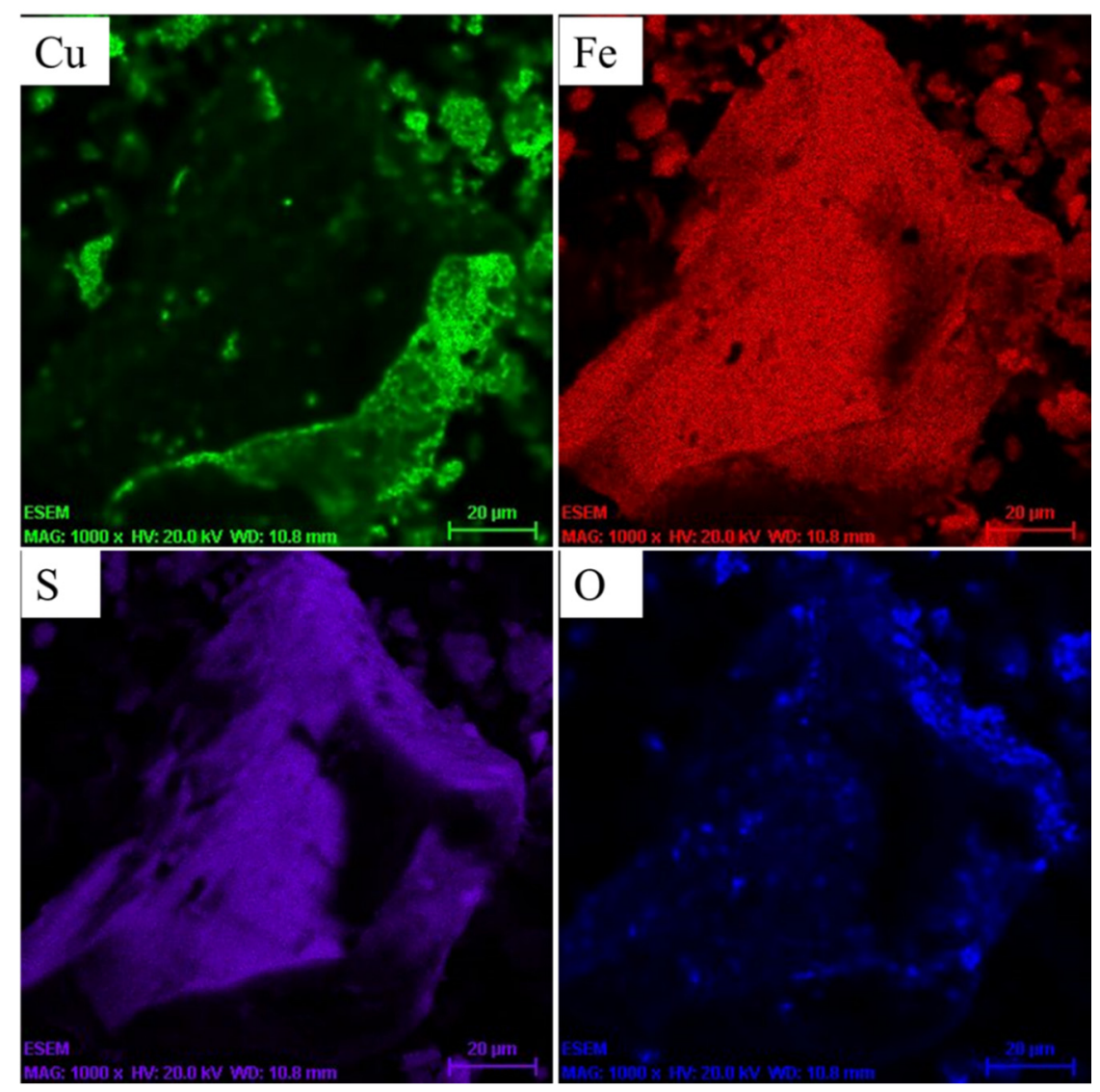

Figure 3. EDS mapping of the chalcopyrite-bearing ore.

\subsection{Experimental Design}

The four independent variables in the UAL and non-UAL experiments were ultrasonic power, S/L ratio, sulfuric acid concentration, and leaching temperature.

1. The effect of ultrasonic power was studied at four amplitudes (0, 20, 40, and 70\%) at 10\% S/L, $0.5 \mathrm{M}$ sulfuric acid concentration, $50{ }^{\circ} \mathrm{C}$ leaching temperature, and $800 \mathrm{rpm}$ stirring speed.

2. Non-UAL (power $0 \%$ ) and UAL (power 20\%) experiments tested the effect of S/L $(0.1,1.0,5.0$, and $10 \%$ ) at $0.5 \mathrm{M}$ sulfuric acid concentration, $50{ }^{\circ} \mathrm{C}$ leaching temperature, and $800 \mathrm{rpm}$ stirring speed. 
3. Non-UAL (power $0 \%$ ) and UAL (power 20\%) experiments tested the effects of the sulfuric acid concentration $\left(0.01,0.1,0.5\right.$, and $\left.1.0 \mathrm{M} \mathrm{H}_{2} \mathrm{SO}_{4}\right)$ at $1 \% \mathrm{~S} / \mathrm{L}, 50^{\circ} \mathrm{C}$ leaching temperature, and $800 \mathrm{rpm}$ stirring speed.

4. Non-UAL (power $0 \%$ ) and UAL (power 20\%) experiments tested the effect of leaching temperature $\left(50,65\right.$, and $\left.80^{\circ} \mathrm{C}\right)$ at $1 \% \mathrm{~S} / \mathrm{L}, 0.5 \mathrm{M}$ sulfuric acid concentration, and $800 \mathrm{rpm}$ stirring speed.

\subsection{Experimental Procedure}

Chalcopyrite ore samples ( $300 \mathrm{~g}$ ) were crushed, sieved to $+53 /-75 \mu \mathrm{m}$, and stored in a $-25^{\circ} \mathrm{C}$ freezer to prevent sulfide oxidation. Prior to leaching tests, samples were dried at $40{ }^{\circ} \mathrm{C}$ for $24 \mathrm{~h}$. The sulfuric acid solution was prepared with concentrated $98 \%$ sulfuric acid diluted with deionized water.

Five-hour leaching experiments were performed in duplicate in a $500-\mathrm{mL}$ jacketed glass reactor with a $200 \mathrm{~mL}$ sulfuric acid solution in a thermostatic water bath on a hot plate with a magnetic stirrer (Figure 4). The $400 \mathrm{~W}$ ultrasonic processor (UP400S, Hielscher Ultrasound Technology, Teltow, Germany) worked at a constant frequency of $24 \mathrm{kHz}$. It had a 22-mm diameter probe with a vibrating titanium tip attached to the transducer. The energy input was varied by changing the amplitude of the sonotrode, which was positioned at a depth of approximately $2.5 \mathrm{~cm}$ into the solution.

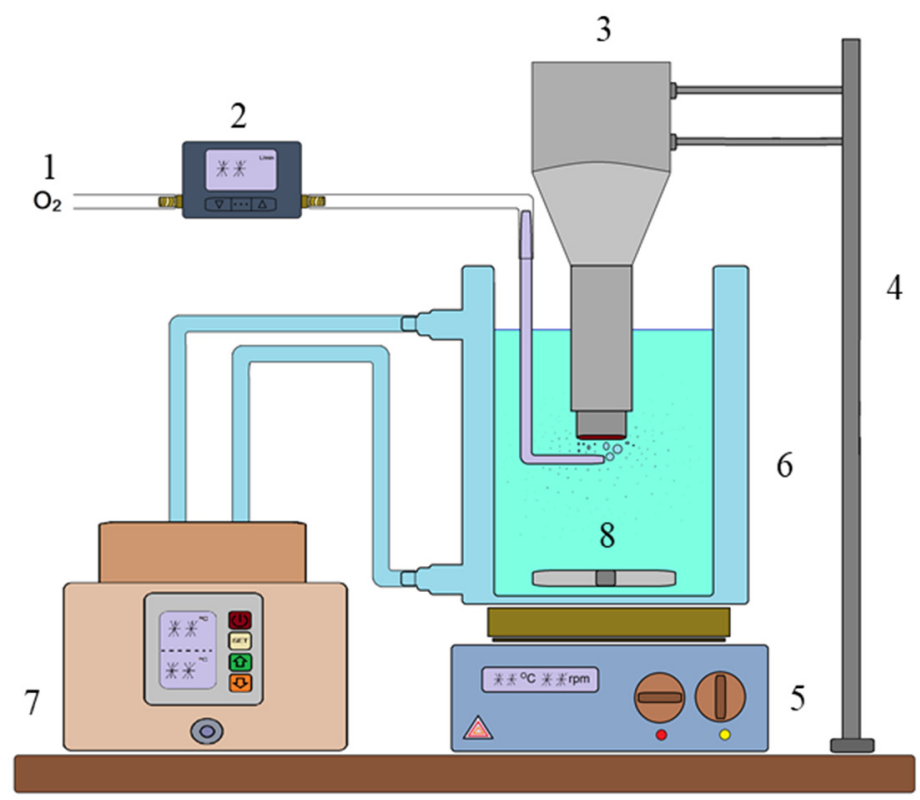

Figure 4. Schematic diagram of experimental leaching system: 1-oxygen cylinder; 2-gas flow meter; 3-ultrasonic processor; 4-test bench; 5-hot plate; 6-jacketed reactor; 7—thermostatic bath; 8 -magnetic stirrer.

After the required temperature was achieved, a certain amount of chalcopyrite was added to a $0.0125 \mathrm{M}$ ferric sulfate solution depending on the $\mathrm{S} / \mathrm{L}$. Oxygen was sparged continuously into the leaching reactor at a flow rate of $0.5 \mathrm{~L} / \mathrm{min}$. A total of $5 \mathrm{~h}$ leaching time was chosen since there was no significant increase after that in the preliminary experiments. At the $1,2,3$, and $5 \mathrm{~h}$ time points, the leaching solution $\mathrm{pH}$, oxidation/reduction potential (ORP), and DO concentration were measured, and $10-\mathrm{mL}$ aliquots of the solution were withdrawn (and replaced with $10 \mathrm{~mL}$ fresh solution) with a syringe, centrifuged at $6000 \mathrm{rpm}$ for $2 \mathrm{~min}$, and filtered through $0.45 \mu \mathrm{m}$ syringe filters to remove the insoluble particles. The filtrate was analyzed for dissolved $\mathrm{Cu}$ and $\mathrm{Fe}$ concentrations with a microwave plasma atomic emission spectroscope (Agilent Technologies 4200, USA) to determine the extraction yield of $\mathrm{Cu}$ and $\mathrm{Fe}$. At the end of the leaching experiments, solutions were vacuum filtered, and the residue was recovered, washed with deionized water several times, and dried at room temperature prior to further analysis. 
The Cu extraction, E (\%), was calculated according to Equation (4).

$$
E=\frac{C \times V}{P \times M} \times 100
$$

where, $E$ is the $\mathrm{Cu}$ extraction (\%), $\mathrm{C}$ is the $\mathrm{Cu}$ concentration in the leaching solution $(\mathrm{g} / \mathrm{L}), V$ is the volume of leaching solution (L), $P$ is the Cu percentage of the chalcopyrite ore (\%), and $M$ is the amount of added chalcopyrite ore (g).

\subsection{Analysis and Characterization}

The mineralogical composition and crystallinity of the leached residues were measured on powdered samples by XRD using an X'Pert Pro Philips powder diffractometer (Philips, Egham, UK) with $\mathrm{Co} \mathrm{K} \alpha$ radiation in the testing $2 \theta$ range of $5-80^{\circ}$ at a scan rate of $0.017^{\circ} / \mathrm{min}$. Morphological characteristics were investigated by SEM with EDS after carbon coating. The total sulfur content in the residue was analyzed using an ELTRA CS-2000 Induction Furnace (Eltra GmbH, Haan, Germany), while the elemental sulfur content was determined by Thermogravimetric Analysis (TGA) using a Netzsch STA 449 F3 Jupiter model (NETZSCH-Geraetebau GmbH, Selb, Germany). All values are reported as the means of duplicate samples.

\section{Results and Discussion}

\subsection{Effect of Leaching Parameters on Copper Extraction}

\subsubsection{Effect of Ultrasonic Power}

Ultrasound-enhanced $\mathrm{Cu}$ extraction from chalcopyrite-bearing ore. After $5 \mathrm{~h}$ of leaching, $\mathrm{Cu}$ extraction was $5.9 \%$ higher at the highest UAL treatment compared to the non-UAL treatment $(25.5 \%$ and $19.6 \% \mathrm{Cu}$ extraction, respectively: Figure 5). Cu extraction increased with ultrasonic power amplitude and followed the same pattern among all treatments. At each amplitude, the increase in $\mathrm{Cu}$ extraction is the most dramatic in the first hour of leaching, and more slowly thereafter. However, the overall $\mathrm{Cu}$ recovery did not exhibit a substantial increase with the different ultrasonic power amplitudes.

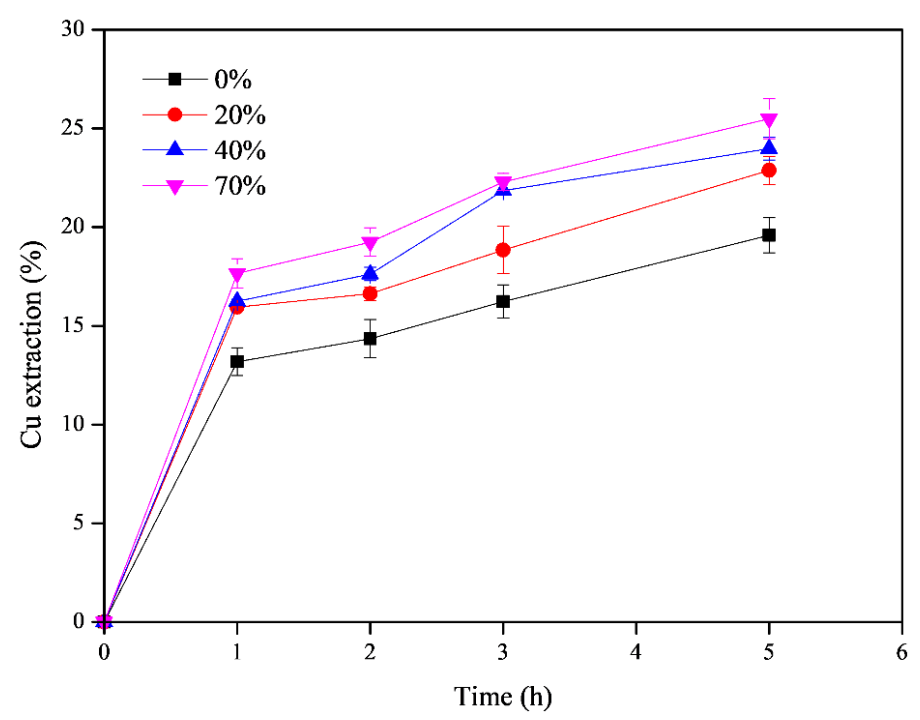

Figure 5. Copper extraction versus leaching time without ( $0 \%)$ and with ultrasound assistance at three power amplitudes (leaching conditions: a 10\% solid-to-liquid ratio (S/L), $0.5 \mathrm{M}$ sulfuric acid concentration, $50{ }^{\circ} \mathrm{C}$, and $800 \mathrm{rpm}$ stirring speed).

These results are consistent with previous studies showing that ultrasonic power either accelerates $\mathrm{Cu}$ dissolution within a short period or shortens the time to reach a given $\mathrm{Cu}$ recovery [29]. This effect 
could be attributed to ultrasound treatment decreasing the resistance to mass transfer in the system or removing insoluble substances from the solid surfaces. Therefore, dissolution of the mineral and regeneration of ferric ions are enhanced, which combine to increase species transfer in the system.

\subsubsection{Effect of the Solid-to-Liquid Ratio}

Without ultrasound assistance, mean $\mathrm{Cu}$ recoveries after a $5 \mathrm{~h}$ leach at the four tested S/L ratios were less than $22 \%$ (Figure 6a). Whereas the three lowest $\mathrm{S} / \mathrm{L}$ ratios yielded similar $\mathrm{Cu}$ recoveries, the highest S/L tested, $10 \%$, resulted in a slightly lower $\mathrm{Cu}$ recovery (19.6\% Cu recovery). The stoichiometric requirement for the reaction probably resulted in a late-stage, acid-deficient condition [22]. In the UAL treatment, the highest S/L also yielded the lowest $\mathrm{Cu}$ recovery, but an $\mathrm{S} / \mathrm{L}$ of $0.1 \%$ resulted in a dramatically higher $\mathrm{Cu}$ recovery (40.7\%) than the other three S/L ratios (Figure $6 \mathrm{~b}$ ). This could be due to the synergistic impacts of the reduced viscosity of the slurry and ultrasound-induced cavitation that eliminated the diffusional mass transfer resistance and promoted the diffusion of $\mathrm{Cu}$ ions.
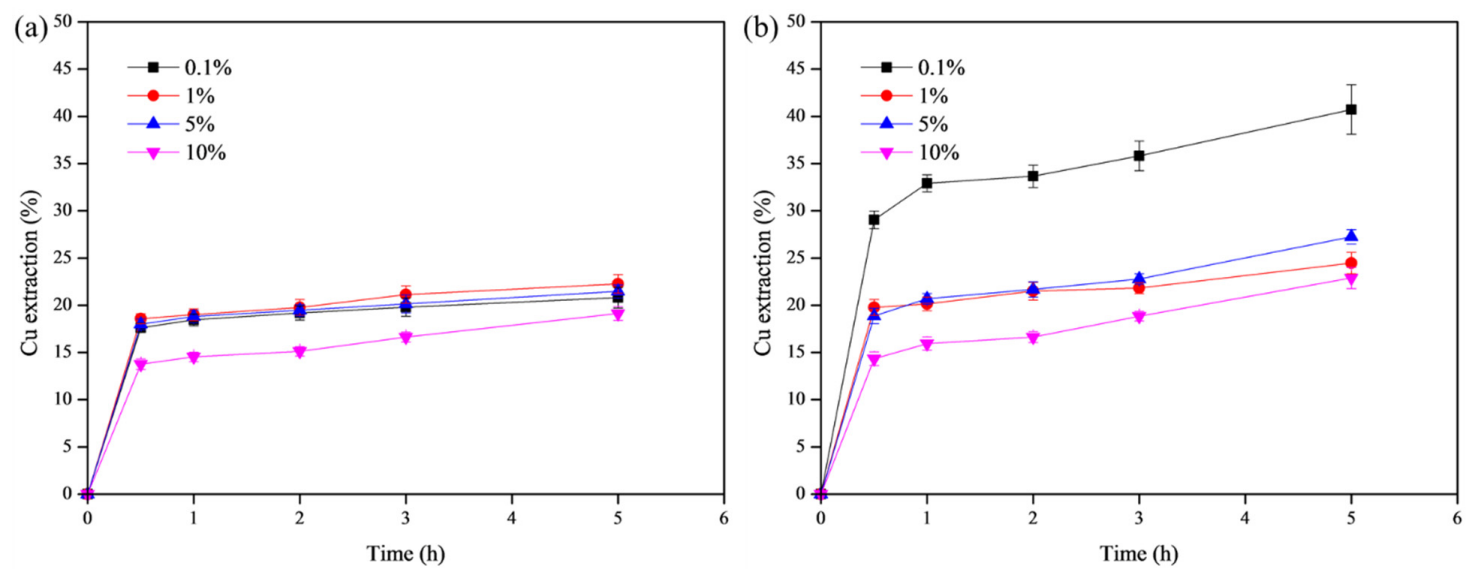

Figure 6. Copper extraction versus leaching time at four solid/liquid ratios (a) without and (b) with ultrasound assistance at 20\% power amplitude (leaching conditions: $0.5 \mathrm{M}$ sulfuric acid concentration, $50{ }^{\circ} \mathrm{C}$, and $800 \mathrm{rpm}$ stirring speed).

\subsubsection{Effect of Acid Concentration}

At all the tested concentrations, $\mathrm{Cu}$ extractions are higher in UAL than non-UAL systems. However, acid concentration had little effect on $\mathrm{Cu}$ recovery. In the non-UAL treatment, the maximum $\mathrm{Cu}$ recovery $(22.3 \%)$ was obtained at $0.5 \mathrm{M}$ sulfuric acid after a 5 -h leach; the $0.01,0.1$, and $1.0 \mathrm{M}$ concentrations yielded similar recoveries (Figure 7a). In the UAL treatment, the maximum Cu recovery was $26.4 \%$ at $0.01 \mathrm{M}$ sulfuric acid, which is a $4.1 \%$ improvement over the non-UAL maximum recovery (Figure $7 \mathrm{~b}$ ). Thus, UAL at a $20 \%$ power amplitude lowered acid consumption, which is consistent with previous studies [30]. The chief function of sulfuric acid in the leach is to prevent hydrolysis and precipitation of ferric ions, but the DO leaching pathway (Equation (2)) and gangue minerals may also consume acid [31]. 

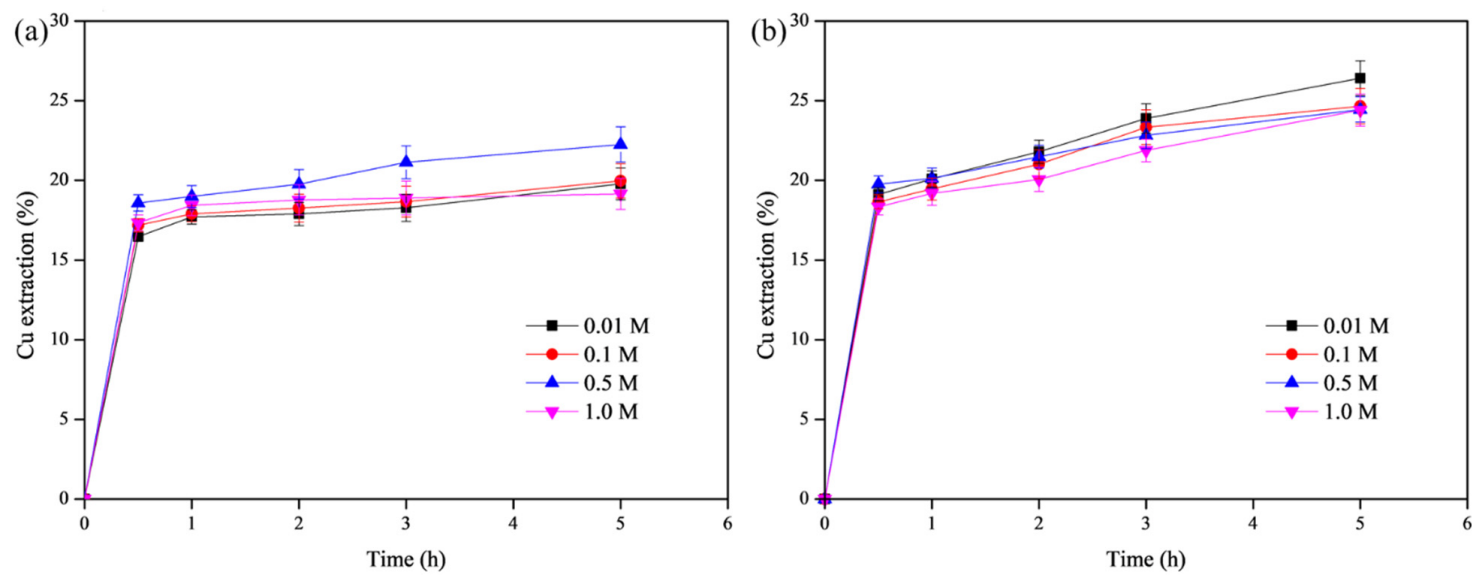

Figure 7. Copper extraction versus leaching time at four sulfuric acid concentrations (a) without and (b) with ultrasound assistance at $20 \%$ power amplitude (leaching conditions: $1 \% \mathrm{~S} / \mathrm{L}, 50{ }^{\circ} \mathrm{C}$, and 800 rpm stirring speed).

\subsubsection{Effect of Temperature}

$\mathrm{Cu}$ extraction increased dramatically with leaching temperature with and without ultrasound assistance (Figure 8; note change in scale relative to Figures 5-7). The maximum $\mathrm{Cu}$ recovery in the UAL treatment was $57.5 \%$, an increase of $7.1 \%$ compared to the non-UAL treatment $(50.4 \% \mathrm{Cu}$ recovery). Running UAL under these conditions for $4 \mathrm{~h}$ would achieve the same $\mathrm{Cu}$ recovery as the non-UAL treatment. This concurs with research by Yoon et al. [27] on the UAL of chalcopyrite by $\mathrm{FeCl}_{3}$ in a hydrochloric acid solution: the largest increment in Cu recovery by UAL was at the tested maximum temperature of $99^{\circ} \mathrm{C}$. The positive effect of temperature on $\mathrm{Cu}$ recovery could be explained by the smaller difference in DO concentration between the UAL and non-UAL tests at $80^{\circ} \mathrm{C}$ (data not shown). With a sufficient $\mathrm{DO}$, the combined effects of temperature and the physical effects of cavitation are more conducive to dissolving copper by disintegrating larger particles, which facilitates reagent penetration into the interior of particles [32].
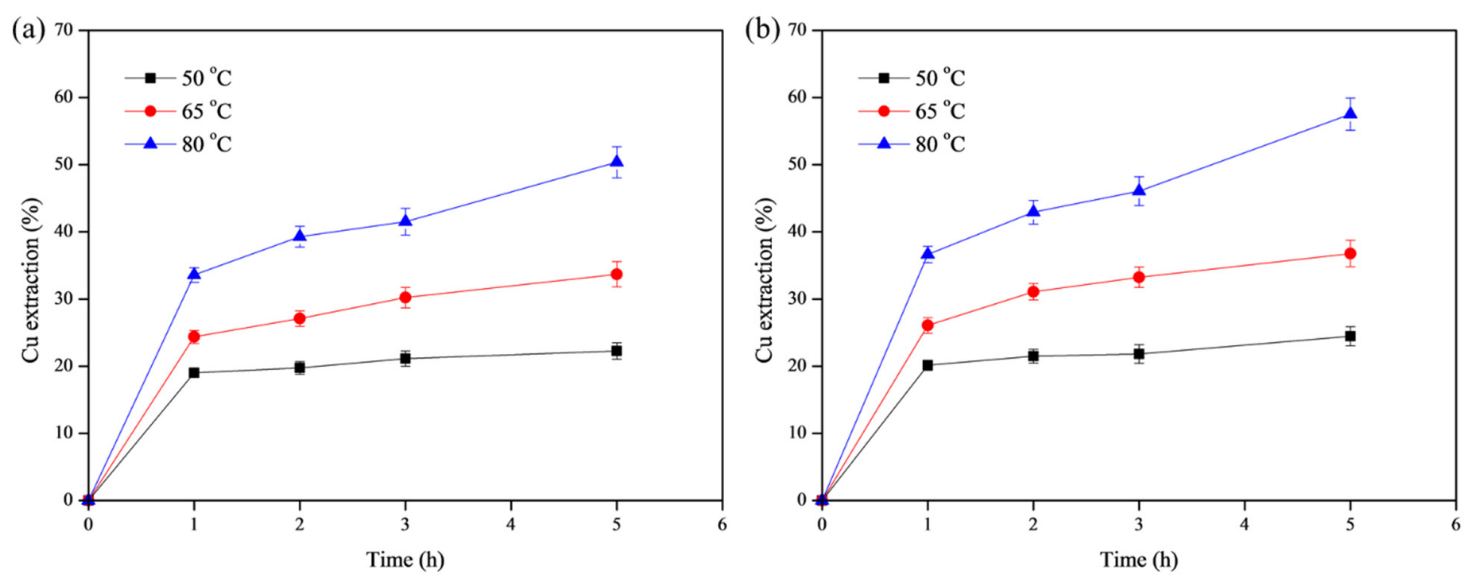

Figure 8. Copper extraction versus leaching time at three leaching temperatures (a) without and (b) with ultrasound assistance at $20 \%$ power amplitude (leaching conditions: $1 \% \mathrm{~S} / \mathrm{L}, 0.5 \mathrm{M}$ sulfuric acid concentration, and 800 rpm stirring speed).

Overall, DO was higher in the non-UAL (Figure 9a) than UAL treatment (Figure 9b). This is to be expected since ultrasound generally influences gassing out more than gassing in, and deaeration by cavitation lowers DO concentrations. A similar trend is evident for OPR (Figure 9). This can be explained by the existence of the redox couple $\mathrm{Fe}^{3+} / \mathrm{Fe}^{2+}$ since UAL could possibly energize the ions increasing the activities of $\mathrm{Fe}^{3+}$ and $\mathrm{Fe}^{2+}$ in chalcopyrite leaching, which can add complexity to the 
leaching system. Three reactions can occur simultaneously: reduction of $\mathrm{Fe}^{3+}$ to $\mathrm{Fe}^{2+}$, oxidation of $\mathrm{Fe}^{2+}$ to $\mathrm{Fe}^{3+}$, and oxidation of the mineral [33,34]. In the UAL treatment, the higher Cu recovery implies that more $\mathrm{Fe}^{3+}$ was consumed during the leach. This lowered the $\mathrm{Fe}^{3+} / \mathrm{Fe}^{2+}$ ratio and eventually led to a lower ORP. However, $\mathrm{pH}$ did not differ between the non-UAL and UAL treatments (data not shown), though $\mathrm{pH}$ increased slightly as the leaching reactions progressed due to acid consumption.
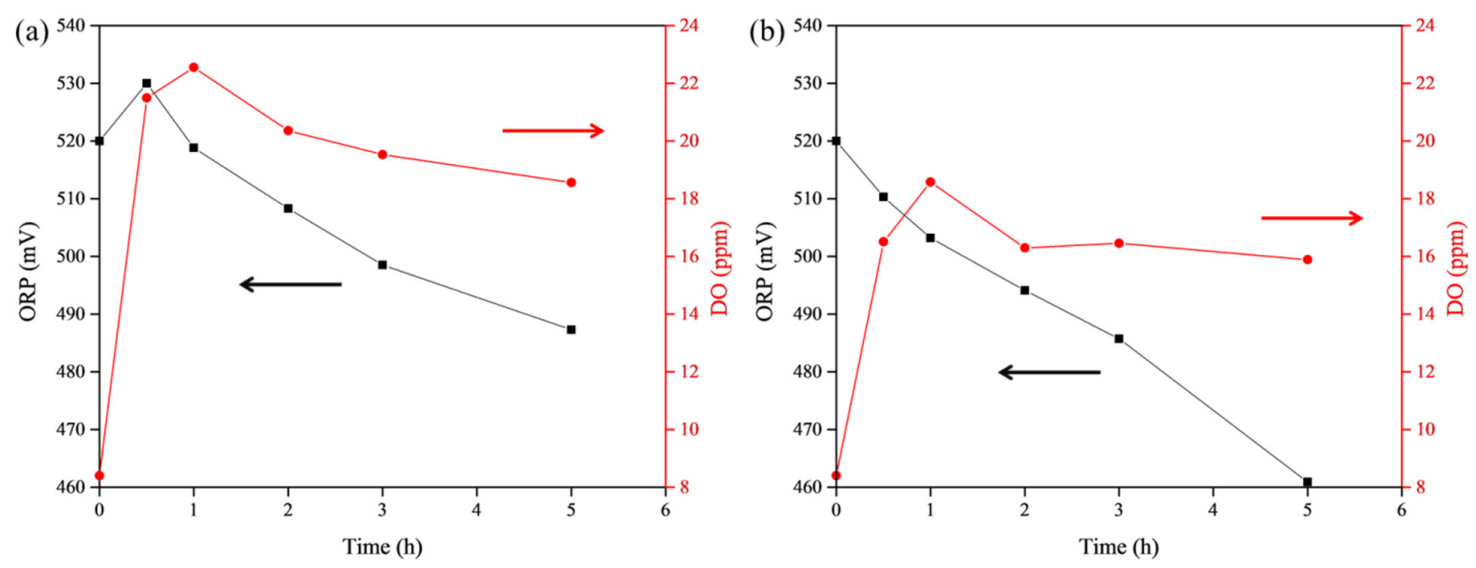

Figure 9. Oxidation/reduction potential (ORP) and dissolved oxygen (DO) concentration versus leaching time (a) without and (b) with ultrasound assistance at $20 \%$ power amplitude (leaching conditions: $1 \% \mathrm{~S} / \mathrm{L}, 0.5 \mathrm{M}$ acid concentration, $50{ }^{\circ} \mathrm{C}$, and $800 \mathrm{rpm}$ stirring speed).

\subsubsection{Leaching Results Summary}

Overall, the relative impact of the leaching parameters on $\mathrm{Cu}$ recovery over a 5-h leach was temperature $>$ ultrasound power $>\mathrm{S} / \mathrm{L}>$ acid concentration. The optimal conditions tested, weighing $\mathrm{Cu}$ recovery against acid consumption and ultrasound power requirements, are as follows: ultrasound power amplitude $20 \%, 1 \% \mathrm{~S} / \mathrm{L}, 0.5 \mathrm{M} \mathrm{H}_{2} \mathrm{SO}_{4}$ concentration, and temperature $80{ }^{\circ} \mathrm{C}$. Under these conditions, after $5 \mathrm{~h}$, the $\mathrm{Cu}$ recovery was $57.5 \%$, an increase of $7.1 \%$ to the non-UAL treatment $(50.4 \%$ $\mathrm{Cu}$ recovery). Ultrasound also reduced the leaching time by $1 \mathrm{~h}$ to attain the same leaching rate as the no ultrasound test.

\subsection{Residue Characterization}

XRD and SEM were used to characterize residues from UAL and non-UAL under the optimal leaching conditions tested; results were compared to residues from a $50{ }^{\circ} \mathrm{C}$ leach to determine if there is a synergistic effect of temperature and ultrasound. Chalcopyrite was not easily dissolved in any of the four treatments: The main phase species of chalcopyrite ore were not affected by ultrasonication or temperature (Figure 10). The relative intensity of the main chalcopyrite peak was lower in UAL than non-UAL treatments, and the weak peaks were lost, which indicates that UAL enhanced Cu leaching. The peak intensities of pyrite were similar among treatments. Some quartz peaks disappeared in all treatments, possibly by mechanical collision. 

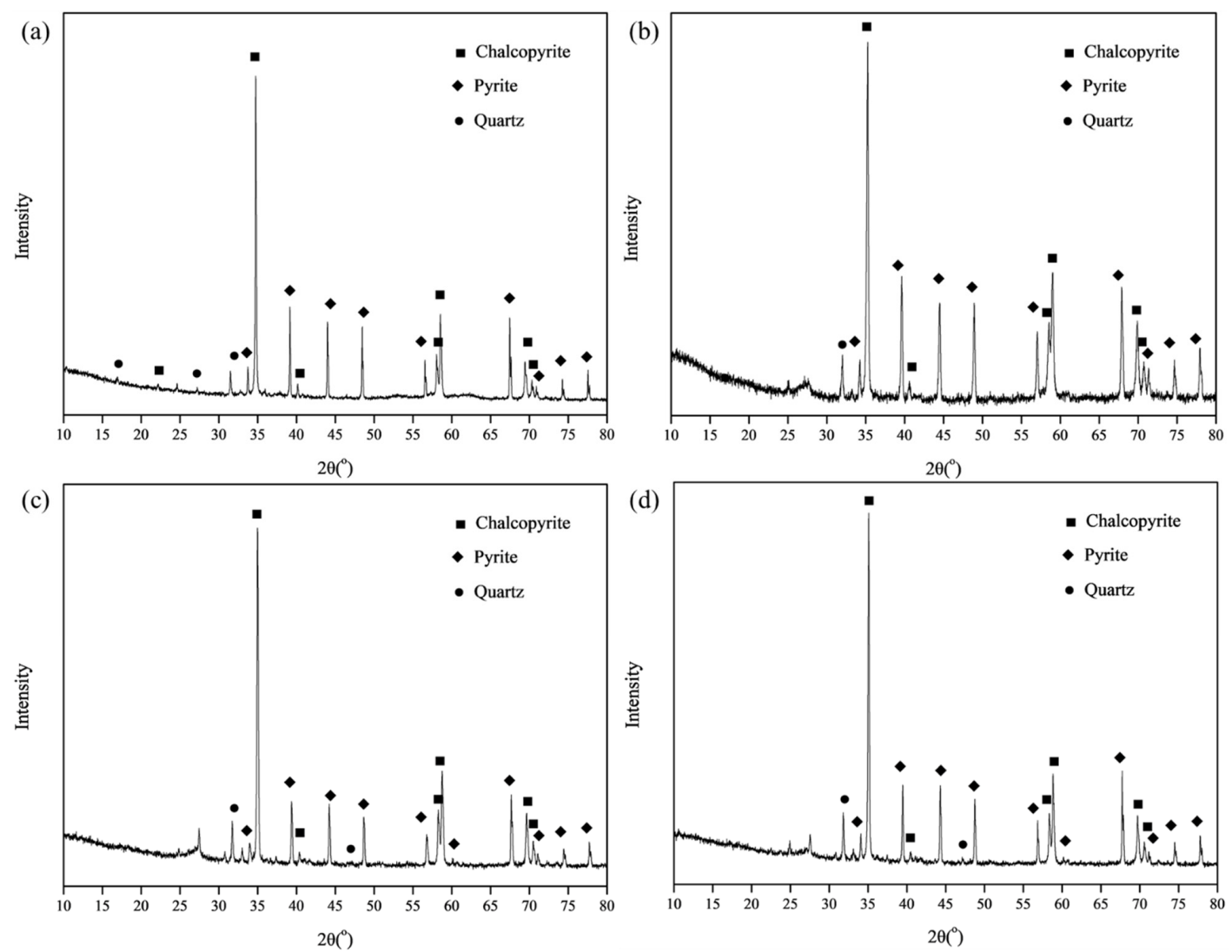

Figure 10. X-ray diffraction patterns of the chalcopyrite-leached residues: (a) non-UAL at $50{ }^{\circ} \mathrm{C}$; (b) UAL at $50{ }^{\circ} \mathrm{C}$; (c) non-UAL at $80{ }^{\circ} \mathrm{C}$; and (d) UAL at $80{ }^{\circ} \mathrm{C}$ (leaching conditions: ultrasound power amplitude $20 \%, 1 \% \mathrm{~S} / \mathrm{L}, 0.5 \mathrm{M}$ sulfuric acid concentration, and $800 \mathrm{rpm}$ stirring speed). UAL_ultrasound-assisted leaching.

A high temperature combined with ultrasound produce a synergic effect on particle size. The overall particle size of the leached chalcopyrite residues from all four treatments decreased to $30-50 \mu \mathrm{m}$ from the original particle size of 53-75 $\mu \mathrm{m}$ (Figure 11). The particle size of the residues was smaller for the UAL at $80^{\circ} \mathrm{C}$ (Figure 11d) than for the other three treatments. Microcracks within particles were deeper at $80^{\circ} \mathrm{C}$ than $50{ }^{\circ} \mathrm{C}$. UAL residues had a rough, loose, and porous structure, probably from cavitation-induced surface damage and particle fragmentation [32]. This structure would facilitate contact of the exposed $\mathrm{Cu}$ to the reagent, enhancing $\mathrm{Cu}$ dissolution. However, small globules extensively covered the pores in all treatments; these could suppress the diffusion of reagent into the interior to react with the unreacted ore [35]. Extensive pyrite coverage over the surface (see Figure 2) may also slow $\mathrm{Cu}$ leaching through the product layer as indicated by [36]. This evidence clearly demonstrates ultrasonic cavitation as the main effect in promoting chalcopyrite leaching by increasing the particle diffusion and mass transfer rate. 

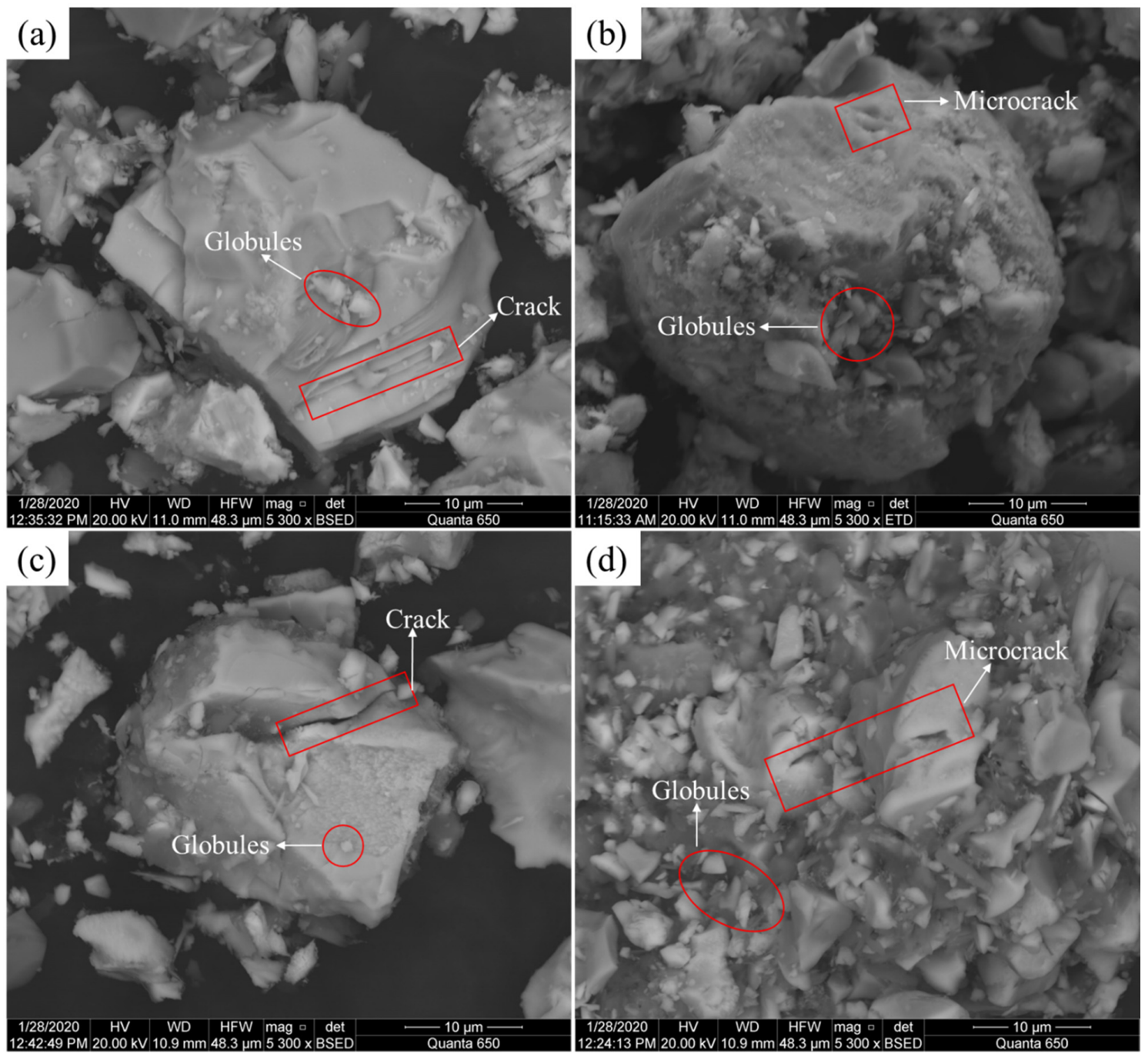

Figure 11. Scanning electron micrographs of the chalcopyrite-leached residues: (a) non-UAL at $50{ }^{\circ} \mathrm{C}$; (b) UAL at $50{ }^{\circ} \mathrm{C}$; (c) non-UAL at $80^{\circ} \mathrm{C}$; and (d) UAL at $80{ }^{\circ} \mathrm{C}$ (leaching conditions: ultrasound power amplitude $20 \%, 1 \% \mathrm{~S} / \mathrm{L}, 0.5 \mathrm{M}$ sulfuric acid concentration, and $800 \mathrm{rpm}$ stirring speed).

The total sulfur content was slightly higher in UAL than non-UAL residues, whereas the opposite was true for elemental sulfur (Table 2). Differences were more exaggerated at the higher leaching temperature. Therefore, another mechanism by ultrasonic cavitation in UAL promoting $\mathrm{Cu}$ dissolution is through the removal of elemental sulfur, which plays a barrier role in the ore leaching process; the removed elemental sulfur floating in the solution is much easier to be oxidized under the tested conditions.

Table 2. Mass of the sulfur species in the chalcopyrite residues from leaching at two temperatures without (non-UAL) and with (UAL) ultrasound assistance.

\begin{tabular}{cccc}
\hline Treatment & Residue $(\mathrm{g})$ & Total Sulfur $(\mathrm{g})$ & Elemental Sulfur $(\mathrm{g})$ \\
\hline $50{ }^{\circ} \mathrm{C}$, non-UAL & 1.5455 & 0.5687 & 0.0780 \\
\hline $50{ }^{\circ} \mathrm{C}, \mathrm{UAL}$ & 1.5676 & 0.5876 & 0.0361 \\
\hline $80^{\circ} \mathrm{C}$, non-UAL & 1.4641 & 0.4964 & 0.1091 \\
\hline $80^{\circ} \mathrm{C}, \mathrm{UAL}$ & 1.4652 & 0.5778 & 0.0672 \\
\hline
\end{tabular}




\subsection{Kinetic Analysis}

Oxidative leaching of chalcopyrite comprises solid-liquid heterogeneous reactions and is generally controlled by one or more of the following three successive steps:

1. diffusion through the liquid film;

2. diffusion through the ash/product layer (if present); and

3. chemical reaction at the surface of the solid.

Based on the literature $[22,37,38]$ and the SEM images in Figure 11, it is understood that as the leaching proceeds, a product layer forms around the particles in both the UAL and non-UAL tests. A shrinking core model is appropriate for the kinetic analysis of these systems [39]. In this model, each of the three controlling steps above has a corresponding equation (Equations (5), (7), and (9)). The one that best fits the data would be considered the rate controlling step [40].

Liquid film diffusion control:

$$
k_{F} t=X
$$

where

$$
k_{F}=\frac{3 b L C}{\rho R_{0}}
$$

Solid product layer diffusion control:

$$
k_{P} t=1-3(1-X)^{\frac{2}{3}}+2(1-X)
$$

where

$$
k_{P}=\frac{6 b D_{e} C}{\rho R_{0}^{2}}
$$

Chemical reaction control:

$$
k_{R} t=1-(1-X)^{\frac{1}{3}}
$$

where

$$
k_{R}=\frac{b K_{S} C}{\rho R_{0}}
$$

where $k$ is the apparent rate constant for each of the controlling steps, $t$ is the time at which the $X$ fraction of the metal is recovered, $\rho$ is density $\left(\mathrm{kg} / \mathrm{m}^{3}\right), R_{0}$ is the initial radius of particle $(\mathrm{m}), L$ is the mass transfer coefficient in the liquid film $\left(\mathrm{m} \mathrm{s}^{-1}\right), C$ is the concentration of the reactant $\left(\mathrm{kg} / \mathrm{m}^{3}\right), D_{e}$ is the effective diffusion coefficient for porous structures $\left(\mathrm{m}^{2} \mathrm{~s}^{-1}\right)$, and $K_{s}$ is the reaction rate constant at the particle surface $\left(\mathrm{s}^{-1}\right)$. The slope of the line is the rate constant $k_{F}, k_{P}$, or $k_{R}$, while the temperature dependence of the reaction rate constant $\left(k_{d}\right)$ can be calculated using the Arrhenius equation:

$$
k_{d}=A \exp \left(\frac{-E_{a}}{R T}\right)
$$

where $A$ is the frequency factor, $E_{a}$ is the activation energy of the reaction, $R$ is the universal gas constant at $8.31 \mathrm{~J} \mathrm{~mol}^{-1} \cdot \mathrm{K}^{-1}$, and $T$ is the absolute temperature.

To determine the rate-controlling step, Equations (5), (7), and (9) were plotted for all data. Equation (5) did not show a good fit, so diffusion through the liquid film was eliminated as a controlling step. As the leaching reaction proceeds under mechanical stirring and ultrasonication, diffusional resistance through the liquid film should be negligible, therefore it cannot be a limiting step in chalcopyrite leaching [41]. Fitting Equation (7) over time for different temperatures (Figure 12) shows that product layer diffusion is the rate controlling mechanism in both non-UAL and UAL. 
(a)

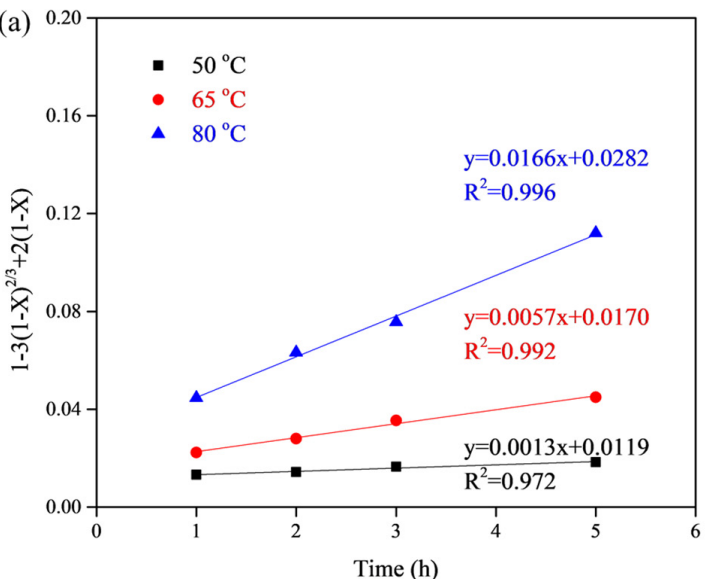

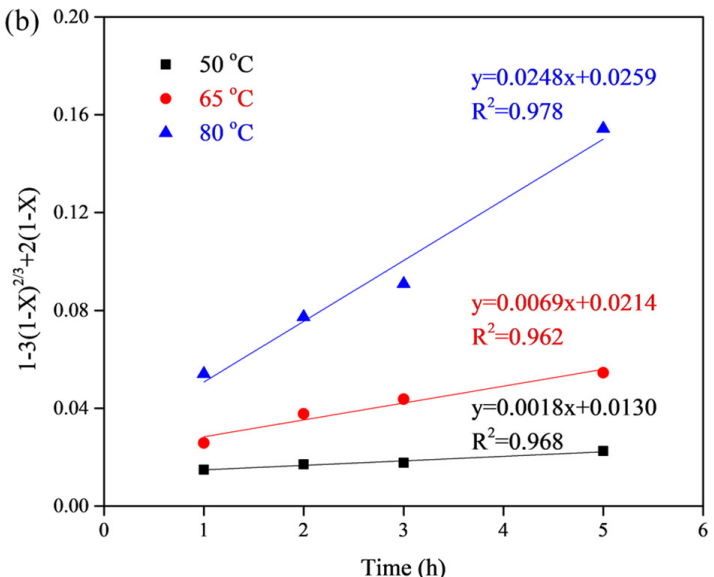

Figure 12. Kinetic constants obtained from fitting the product layer diffusion model (Equation (7)) over time for three temperatures during (a) non-UAL and (b) UAL.

Chemical reactions at the chalcopyrite surface (Equation (9)) also played a role in controlling leaching (Figure 13). This agrees with the SEM results that ultrasound incurs surface damage to generate numerous voids and plaques on the particle surfaces (e.g., Figure 14). In addition, at all tested temperatures, the higher kinetic reaction constant $(\mathrm{k})$ for UAL than non-UAL is also evidence that ultrasound helps to greatly improve the $\mathrm{Cu}$ leaching rate [28]. It is important to highlight that cavitation produced by ultrasonic waves physically crushes particles; thus, it is reasonable to propose that ultrasonic waves remove or at least destroy some parts of the product layer and further accelerate mass transfer and diffusion for more chemical reactions. Other research supports the contention that product layer diffusion or chemical reaction governs the rate of leaching in UAL [22,42]. Comparing the rate determining plots for product layer diffusion control and chemical reaction control, it is understood their $\mathrm{R}^{2}$ values are all high and very close to each other; therefore, neither of them can be distinguished as the only rate limiting step. This implies the mixed control mechanism for both ULA and non-ULA treatments.
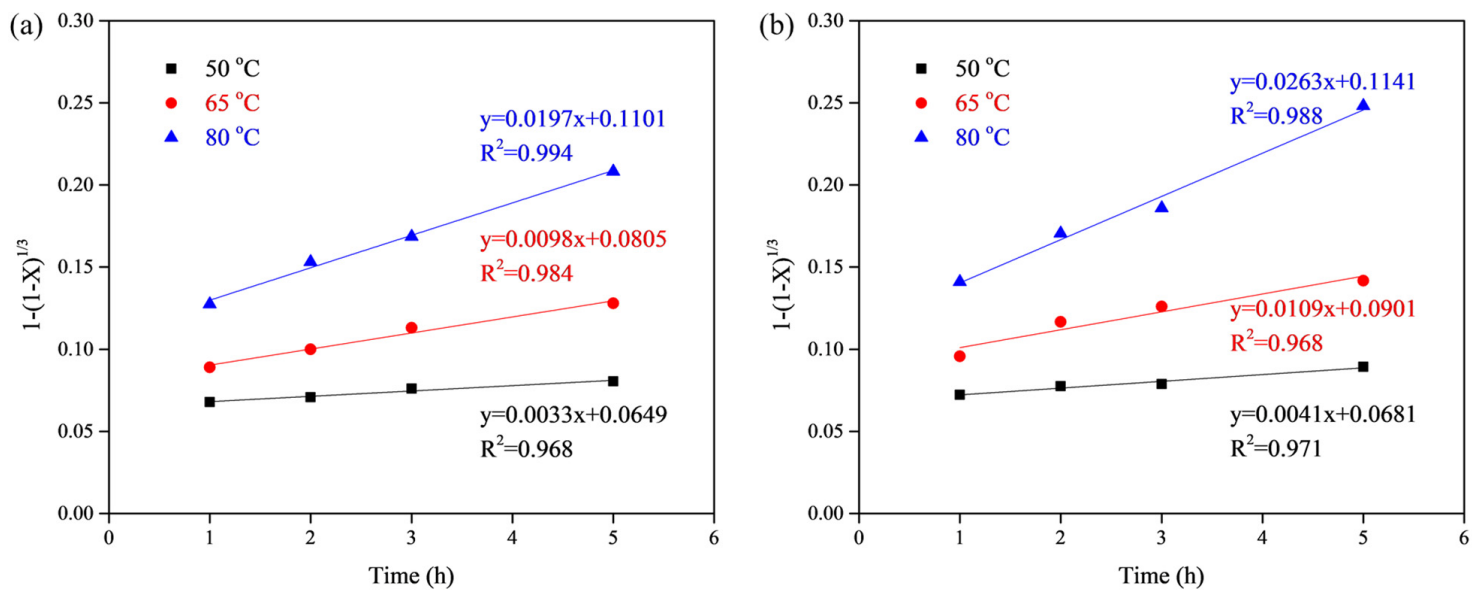

Figure 13. Kinetic constants obtained from fitting the chemical reaction model (Equation (9)) over time for three temperatures during (a) non-UAL and (b) UAL. 


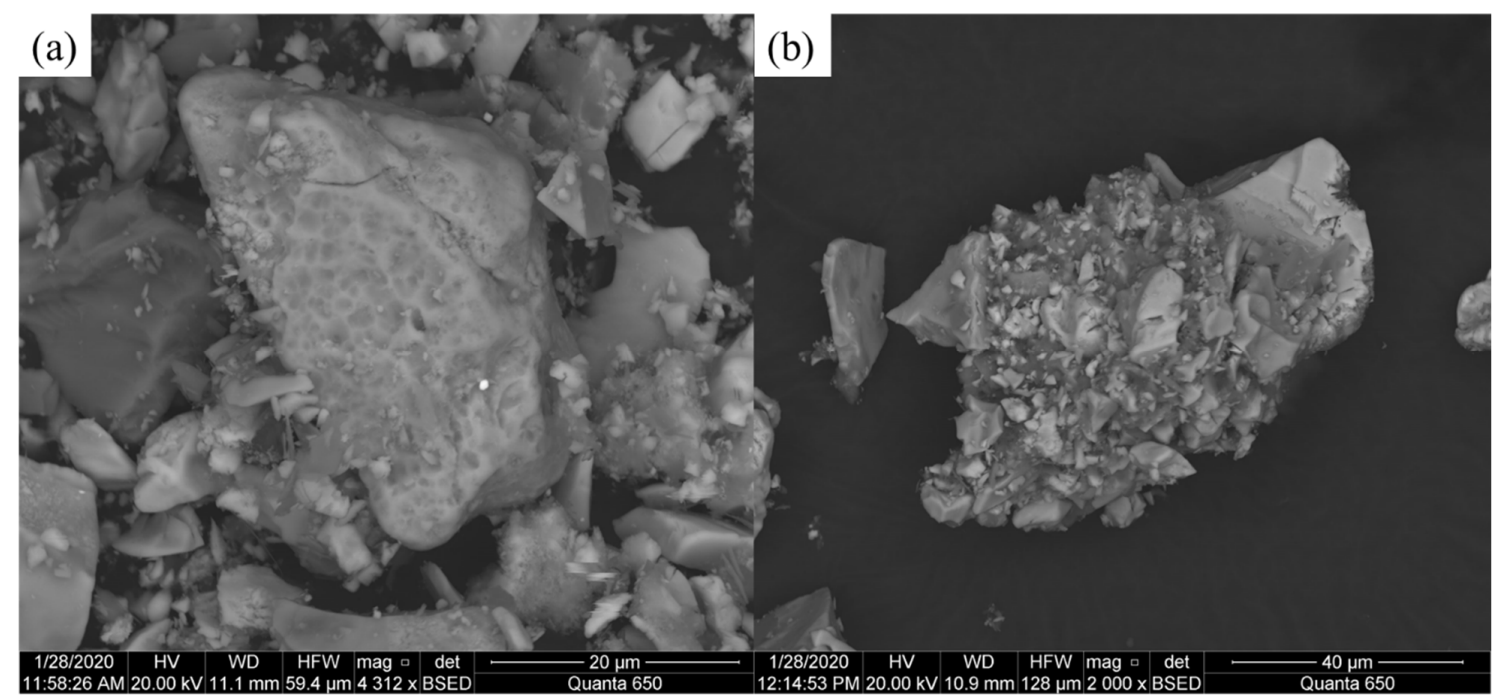

Figure 14. Scanning electron micrographs of the ultrasound-assisted chalcopyrite-leached residue at (a) $50{ }^{\circ} \mathrm{C}$ and (b) $80^{\circ} \mathrm{C}$ (leaching conditions: ultrasound power amplitude $20 \%, 1 \% \mathrm{~S} / \mathrm{L}, 0.5 \mathrm{M}$ sulfuric acid concentration, and $800 \mathrm{rpm}$ stirring speed).

The Arrhenius equation for the non-UAL and UAL processes can be derived (Figure 15) in Equations (12) and (13), respectively.

$$
\begin{gathered}
k_{d}=150392 \exp \left(\frac{-5445.6}{T}\right)(\text { non-UAL }) \\
k_{d}=452254 \exp \left(\frac{-5754.4}{T}\right)(\mathrm{UAL})
\end{gathered}
$$
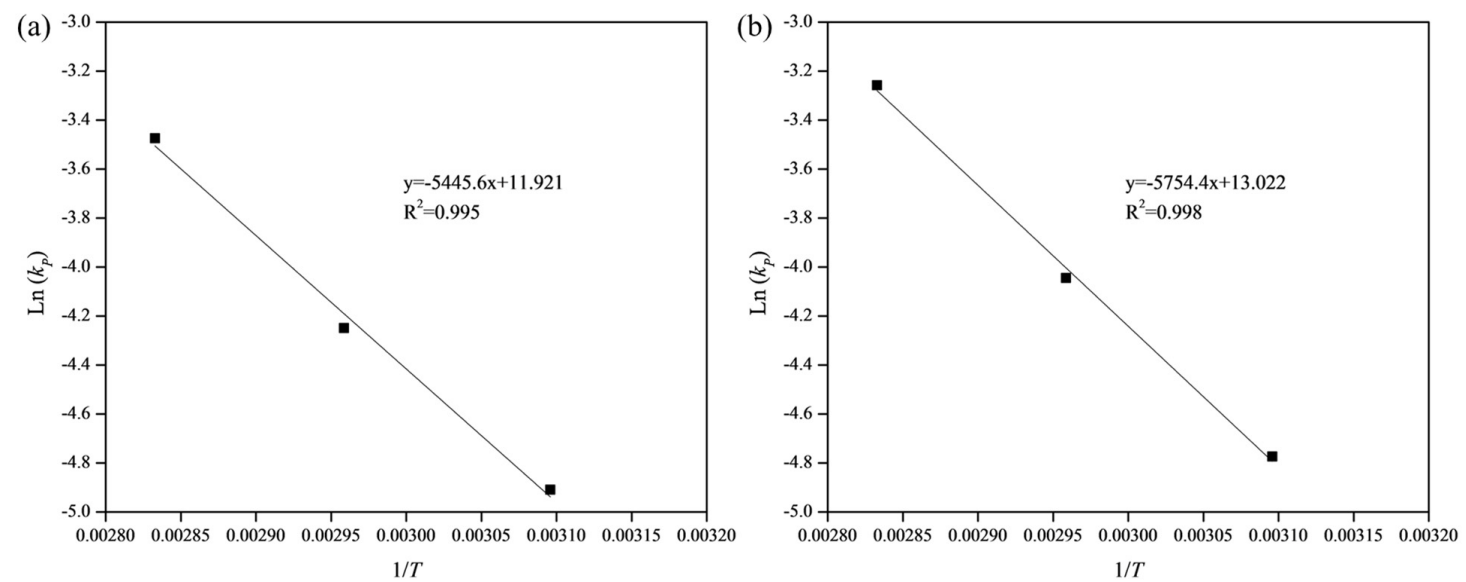

Figure 15. Arrhenius plots from the product layer diffusion obtained for (a) non-UAL and (b) UAL.

Ultrasound treatment had no effect on the activation energy of the reaction, but instead increased the pre-exponential factor $A$ in Equation (11) three-fold. This effect has been reported in many heterogeneous reactions associated with ultrasound [43-45]. Both diffusion through the product layer and chemical reactions control the UAL process. The collision factor can be the collision of $\mathrm{H}^{+}$ions with $\mathrm{SO}_{4}{ }^{2-}$ in the crystal lattice or in the aqueous phase, and maybe the steric factor [43]. 


\section{Conclusions}

Among the experimental leaching conditions tested, the UAL of copper from chalcopyrite over $5 \mathrm{~h}$ in an oxygenated acidic ferric solution was most effective at $20 \%$ amplitude power, an S/L of $1 \%$, a $0.5 \mathrm{M}$ acid concentration, and $80^{\circ} \mathrm{C}$. Under these conditions, the maximum $\mathrm{Cu}$ recovery was $57.5 \%$ compared to $50.4 \%$ for the non-UAL treatment. UAL achieved the same $\mathrm{Cu}$ recovery as the non-UAL in $4 \mathrm{~h}$. Temperature had the greatest effect on copper recovery, followed by ultrasonic power, $\mathrm{S} / \mathrm{L}$, and acid concentration. Improved copper extraction by UAL is mainly attributed to ultrasonic cavitation: breaking up large ore particles to increase the particle diffusion and mass transfer rate, and also removing the formed elemental sulfur layer to enhance the chemical reactions for more chalcopyrite dissolution. The cavitation effect was confirmed by the scanning electron micrographs and elemental sulfur contents of the residues. Kinetics analysis showed that both non-UAL and UAL followed the classical shrinking core model: both product layer diffusion and chemical reactions at the chalcopyrite surface were the rate-controlling mechanism.

Author Contributions: Conceptualization, methodology, validation, writing—original draft preparation, J.W.; software, data analysis, F.F.; and supervision, project administration, writing-review and editing, A.G. All authors have read and agreed to the published version of the manuscript.

Funding: The authors would like to acknowledge the funding of the study by Hatch Inc. (Mississauga, ON, Canada) and MITACS via the fund \# IT13551.

Conflicts of Interest: The authors declare no conflict of interest.

\section{References}

1. Koleini, S.M.J.; Aghazadeh, V.; Sandström, Å. Acidic sulphate leaching of chalcopyrite concentrates in presence of pyrite. Miner. Eng. 2011, 24, 381-386. [CrossRef]

2. Habashi, F. Copper metallurgy at the crossroads. J. Min. Metall. Sect. B Metall. 2007, 43, 1-19. [CrossRef]

3. Wang, S. Copper leaching from chalcopyrite concentrates. JOM 2005, 57, 48-51. [CrossRef]

4. Li, Y.; Kawashima, N.; Li, J.; Chandra, A.P.; Gerson, A.R. A review of the structure, and fundamental mechanisms and kinetics of the leaching of chalcopyrite. Adv. Colloid Interface Sci. 2013, 197-198, 1-32. [CrossRef] [PubMed]

5. Ghahremaninezhad, A.; Dixon, D.G.; Asselin, E. Electrochemical and XPS analysis of chalcopyrite $\left(\mathrm{CuFeS}_{2}\right)$ dissolution in sulfuric acid solution. Electrochim. Acta 2013, 87, 97-112. [CrossRef]

6. Xian, Y.J.; Wen, S.M.; Deng, J.S.; Liu, J.; Nie, Q. Leaching chalcopyrite with sodium chlorate in hydrochloric acid solution. Can. Metall. Q. 2012, 51, 133-140. [CrossRef]

7. Sokić, M.D.; Marković, B.; Živković, D. Kinetics of chalcopyrite leaching by sodium nitrate in sulphuric acid. Hydrometallurgy 2009, 95, 273-279. [CrossRef]

8. Copur, M.; Kizilca, M.; Kocakerim, M.M. Determination of the optimum conditions for copper leaching from chalcopyrite concentrate ore using taguchi method. Chem. Eng. Commun. 2015, 202, 927-935. [CrossRef]

9. Koleini, S.M.J.; Jafarian, M.; Abdollahy, M.; Aghazadeh, V. Galvanic leaching of chalcopyrite in atmospheric pressure and sulfate media: Kinetic and surface studies. Ind. Eng. Chem. Res. 2010, 49, 5997-6002. [CrossRef]

10. Ghomi, M.A.; Mozammel, M.; Moghanni, H.; Shahkar, L. Atmospheric leaching of chalcopyrite in the presence of some polar organic reagents: A comparative study and optimization. Hydrometallurgy 2019, 189, 105120. [CrossRef]

11. Nazari, G.; Dixon, D.G.; Dreisinger, D.B. Enhancing the kinetics of chalcopyrite leaching in the Galvanox ${ }^{\mathrm{TM}}$ process. Hydrometallurgy 2011, 105, 251-258. [CrossRef]

12. Dakubo, F.; Baygents, J.C.; Farrell, J. Peroxodisulfate assisted leaching of chalcopyrite. Hydrometallurgy 2012, 121-124, 68-73. [CrossRef]

13. Naderi, H.; Abdollahy, M.; Mostoufi, N.; Koleini, M.J.; Shojaosadati, S.A.; Manafi, Z. Kinetics of chemical leaching of chalcopyrite from low grade copper ore: Behavior of different size fractions. Int. J. Miner. Metall. Mater. 2011, 18, 638-645. [CrossRef] 
14. Hiroyoshi, N.; Kuroiwa, S.; Miki, H.; Tsunekawa, M.; Hirajima, T. Synergistic effect of cupric and ferrous ions on active-passive behavior in anodic dissolution of chalcopyrite in sulfuric acid solutions. Hydrometallurgy 2004, 74, 103-116. [CrossRef]

15. Mohammadabad, F.K.; Hejazi, S.; Khaki, J.V.; Babakhani, A. Mechanochemical leaching of chalcopyrite concentrate by sulfuric acid. Int. J. Miner. Metall. Mater. 2016, 23, 380-388. [CrossRef]

16. Debernardi, G.; Carlesi, C. Chemical-electrochemical approaches to the study passivation of chalcopyrite. Miner. Process. Extr. Metall. Rev. 2013, 34, 10-41. [CrossRef]

17. Granata, G.; Miura, A.; Liu, W.; Pagnanelli, F.; Tokoro, C. Iodide-assisted leaching of chalcopyrite in acidic ferric sulfate media. Hydrometallurgy 2019, 186, 244-251. [CrossRef]

18. Dixon, D.G.; Mayne, D.D.; Baxter, K.G. Galvanox ${ }^{\mathrm{TM}}$-A novel galvanically-assisted atmospheric leaching technology for copper concentrates. Can. Metall. Q. 2008, 47, 327-336. [CrossRef]

19. Klauber, C. A critical review of the surface chemistry of acidic ferric sulphate dissolution of chalcopyrite with regards to hindered dissolution. Int. J. Miner. Process. 2008, 86, 1-17. [CrossRef]

20. Omran, M.; Fabritius, T.; Elmahdy, A.M.; Abdel-Khalek, N.A.; Gornostayev, S. Improvement of phosphorus removal from iron ore using combined microwave pretreatment and ultrasonic treatment. Sep. Purif. Technol. 2015, 156, 724-737. [CrossRef]

21. Huang, Z.; Xie, F.; Ma, Y. Ultrasonic recovery of copper and iron through the simultaneous utilization of Printed Circuit Boards (PCB) spent acid etching solution and PCB waste sludge. J. Hazard. Mater. 2011, 185, 155-161. [CrossRef]

22. Wang, X.; Srinivasakannan, C.; Duan, X.H.; Yang, J.H.; Yang, D.J.; Ju, S.H. Leaching kinetics of zinc residues augmented with ultrasound. Sep. Purif. Technol. 2013, 115, 66-72. [CrossRef]

23. Tiwari, B.K. Ultrasound: A clean, green extraction technology. TrAC Trends Anal. Chem. 2015, 71, 100-109. [CrossRef]

24. Dogan, H.T.; Kurtbas, A.; Tekin, T. The effect of ultrasound on the dissolution of pyrite ores in acidic and $\mathrm{Fe}_{2}\left(\mathrm{SO}_{4}\right)_{3}$ solutions. Chem. Eng. Technol. 2004, 27, 87-89. [CrossRef]

25. Beşe, A.V. Effect of ultrasound on the dissolution of copper from copper converter slag by acid leaching. Ultrason. Sonochem. 2007, 14, 790-796. [CrossRef] [PubMed]

26. Zhang, J.; Wu, A.-X.; Wang, Y.-M.; Chen, X.-S. Experimental research in leaching of copper-bearing tailings enhanced by ultrasonic treatment. J. China Univ. Min. Technol. 2008, 18, 98-102. [CrossRef]

27. Yoon, H.S.; Kim, C.J.; Chung, K.W.; Lee, J.Y.; Shin, S.M.; Kim, S.R.; Jang, M.H.; Kim, J.H.; Lee, S.I.; Yoo, S.J. Ultrasonic-assisted leaching kinetics in aqueous $\mathrm{FeCl}_{3}-\mathrm{HCl}$ solution for the recovery of copper by hydrometallurgy from poorly soluble chalcopyrite. Korean J. Chem. Eng. 2017, 34, 1748-1755. [CrossRef]

28. Chen, B.; Bao, S.; Zhang, Y.; Li, S. A high-efficiency and sustainable leaching process of vanadium from shale in sulfuric acid systems enhanced by ultrasound. Sep. Purif. Technol. 2020, 240, 116624. [CrossRef]

29. Zhang, R.L.; Zhang, X.F.; Tang, S.Z.; Huang, A.D. Ultrasound-assisted HCl-NaCl leaching of lead-rich and antimony-rich oxidizing slag. Ultrason. Sonochem. 2015, 27, 187-191. [CrossRef]

30. Avvaru, B.; Roy, S.B.; Chowdhury, S.; Hareendran, K.N.; Pandit, A.B. Enhancement of the leaching rate of uranium in the presence of ultrasound. Ind. Eng. Chem. Res. 2006, 45, 7639-7648. [CrossRef]

31. Munoz, P.B.; Miller, J.D.; Wadsworth, M.E. Reaction mechanism for the acid ferric sulfate leaching of chalcopyrite. Metall. Trans. B 1979, 10, 149-158. [CrossRef]

32. Guo, P.; Wang, S.; Zhang, L. Selective removal of antimony from refractory gold ores by ultrasound. Hydrometallurgy 2019, 190, 105161. [CrossRef]

33. Ghahremaninezhad, A.; Dixon, D.G.; Asselin, E. Kinetics of the ferric-ferrous couple on anodically passivated chalcopyrite (CuFeS 2) electrodes. Hydrometallurgy 2012, 125-126, 42-49. [CrossRef]

34. Yue, G.; Asselin, E. Kinetics of ferric ion reduction on chalcopyrite and its influence on leaching up to $150{ }^{\circ} \mathrm{C}$. Electrochim. Acta 2014, 146, 307-321. [CrossRef]

35. Ma, J.; Zhang, Y.; Qin, Y.; Wu, Z.; Wang, T.; Wang, C. The leaching kinetics of K-feldspar in sulfuric acid with the aid of ultrasound. Ultrason. Sonochem. 2017, 35, 304-312. [CrossRef]

36. Cháidez, J.; Parga, J.; Valenzuela, J.; Carrillo, R.; Almaguer, I. Leaching chalcopyrite concentrate with oxygen and sulfuric acid using a low-pressure reactor. Metals 2019, 9. [CrossRef]

37. Nazari, G.; Dixon, D.G.; Dreisinger, D.B. The role of silver-enhanced pyrite in enhancing the electrical conductivity of sulfur product layer during chalcopyrite leaching in the Galvanox ${ }^{\mathrm{TM}}$ process. Hydrometallurgy 2012, 113-114, 177-184. [CrossRef] 
38. Córdoba, E.M.; Muñoz, J.A.; Blázquez, M.L.; González, F.; Ballester, A. Leaching of chalcopyrite with ferric ion. Part III: Effect of redox potential on the silver-catalyzed process. Hydrometallurgy 2008, 93, 97-105. [CrossRef]

39. Safari, V.; Arzpeyma, G.; Rashchi, F.; Mostoufi, N. A shrinking particle-shrinking core model for leaching of a zinc ore containing silica. Int. J. Miner. Process. 2009, 93, 79-83. [CrossRef]

40. Levenspiel, O. Chemical reaction engineering. Ind. Eng. Chem. Res. 1999, 38, 4140-4143. [CrossRef]

41. Zhang, Y.F.; Ma, J.; Qin, Y.H.; Zhou, J.F.; Yang, L.; Wu, Z.K.; Wang, T.L.; Wang, W.G.; Wang, C.W. Ultrasound-assisted leaching of potassium from phosphorus-potassium associated ore. Hydrometallurgy 2016, 166, 237-242. [CrossRef]

42. Golmohammadzadeh, R.; Rashchi, F.; Vahidi, E. Recovery of lithium and cobalt from spent lithium-ion batteries using organic acids: Process optimization and kinetic aspects. Waste Manag. 2017, 64, $244-254$. [CrossRef] [PubMed]

43. Tekin, T.; Tekin, D.; Bayramoğlu, M. Effect of ultrasound on the dissolution kinetics of phosphate rock in $\mathrm{HNO}_{3}$. Ultrason. Sonochem. 2001, 8, 373-377. [CrossRef]

44. Ferrero, F.; Periolatto, M. Ultrasound for low temperature dyeing of wool with acid dye. Ultrason. Sonochem. 2012, 19, 601-606. [CrossRef] [PubMed]

45. Mesci, A.K.; Sevim, F. Dissolution of magnesia in aqueous carbon dioxide by ultrasound. Int. J. Miner. Process. 2006, 79, 83-88. [CrossRef]

(C) 2020 by the authors. Licensee MDPI, Basel, Switzerland. This article is an open access article distributed under the terms and conditions of the Creative Commons Attribution (CC BY) license (http://creativecommons.org/licenses/by/4.0/). 